1 еечение врожденных меланоцитарных невусов у детей двухволновым изиучением мазера на парах меди

Пономарев И.В. ${ }^{1}$ Топчий С.Б. ${ }^{1}$, Пушкарева А.Е. ${ }^{2}$, Андрусенко Ю.Н. ${ }^{3}$, Шакина Л.Д. ${ }^{4}$

\footnotetext{
1 Физический институт имени П. Н. Лебедева Российской академии наук

119991, Россия, г. Москва, Ленинский проспект, д. 53

${ }^{2}$ Национальный исследовательский Университет ИТМО

197101, Россия, г. Санкт-Петербург, Кронверкский проспект, д. 49

${ }^{3}$ Медицинский центр «Институт Здоровья»

61000, Украина, г. Харьков, площадь Конституции, д. 26

${ }^{4}$ Национальный медицинский исследовательский центр здоровья детей

119991, Россия, г. Москва, Ломоносовский проспект, д. 2
}

\begin{abstract}
Абстракт. Врожденные меланоцитарные невусы (ВМН) выявляются при рождении или вскоре после рождения у $1 \%$ новорожденных. Локализация ВМН в эстетически значимых зонах становится причиной снижения самооценки ребенка и вызывает беспокойство его родителей. Хирургическое иссечение участков кожи с ВМН связано с повышенным риском косметических побочных эффектов и нередко приводит к развитию длительных стрессовых состояний у детей после оперативного лечения.
\end{abstract}

Цель исследования. Оценить эффективность лечения ВМН у детей и подростков двухволновым излучением лазера на парах меди (ЛПМ).

Методы. Лечение ВМН среднего размера (до 9 см) было проведено у девяти светлокожих пациентов: у семи девочек и двух мальчиков, в возрасте от 2 месяцев до 16 лет. Процедуры проводили при средней мощности ЛПМ 0,6-1,0 Вт, при соотношении мощности излучений 3:2 на длинах волн 511 нм и 578 нм, экспозиции - 0,2-0,3 с. Диаметр светового пятна - 1 мм. Лечение проводилось за 2-10 сеансов с интервалом 1-2 месяца между сеансами.

Результаты. У детей и подростков лечение ВМН двухволновым излучением ЛПМ позволило добиться существенного осветления в области патологического очага, без формирования гипертрофрических рубцов. Продолжительность заживления кожи в области лазерного воздействия составила 2-3 недели. Побочные эффректы были выражены малозаметной атрофией кожи.

Вывод. Высокая эффективность лазерного лечения малых ВМН в эстетически значимых зонах у детей с помощью двухволнового излучения лазера на парах меди при отсутствии выраженных побочных эфрфектов в виде рубцов или поствоспалительной гиперпигментации позволяет использовать этот метод в клинической практике детских дерматологов и косметологов.

Ключевые слова: лазер на парах меди, лечение пигментных дефектов кожи, врожденные меланоцитарные невусы.

Конфликт интересов: авторы заявляют об отсутствии потенциального конфликта интересов, требующего раскрытия в данной статье.

Для цитирования: Пономарев И.В., Топчий С.Б., Пушкарева А.Е., Андрусенко Ю.Н., Шакина Л.Д. Лечение врожденных меланоцитарных невусов у детей двухволновым излучением лазера на парах меди. Вестник дерматологии и венерологии. 2020; 96 (3): 43-52. https://doi.org/10.25208/vdv1133 


\title{
1 reatment of congenital melanocytic nevus in infants and children by a dual-wavelengths copper vapor laser
}

\author{
Igor V. Ponomarev ${ }^{1}$, Sergei B. Topchy ${ }^{1}$, Alexandra E. Pushkareva², Yury N. Andrusenko ${ }^{3}$, Ludmila D. Shakina ${ }^{4}$
}

\author{
1 P.N. Lebedev Physical Institute of the Russian Academy of Sciences \\ Leninskiy pr., 53, Moscow, 119991, Russia \\ 2 ITMO University \\ Kronverkskiy pr., 49, St. Petersburg, 197101, Russia \\ ${ }^{3}$ Medical Center "Health Institute" \\ Constitution sq., 26, Kharkiv, 61000, Ukraine \\ ${ }^{4}$ National Medical Research Center of Children's Health \\ Lomonosovskiy pr., 2, Moscow, 119991, Russia
}

Introduction. Congenital melanocytic nevus (CMN) is detected at birth or shortly after birth in $1 \%$ of infants. The localization of CMN in aesthetically significant areas causes a decline in child self-esteem and causes concern for his parents. Surgical excision of skin areas with $\mathrm{CMN}$ is associated with an increased risk of cosmetic side effects and is often followed by long-term stress conditions after the invasive intervention.

Aim of the study. To evaluate the efficacy of the CMN removal in infants, children and adolescents with the dual-wavelengths copper vapor laser $(\mathrm{CVL})$ radiation.

Patients and Methods. Medium-sized (up to $9 \mathrm{~cm}$ ) single CMN was treated in nine fair-skinned patients: seven girls and two boys, aged from 2 months to 16 years. The procedures were carried out at an average CVL power of $0.6-1.0 \mathrm{~W}$, with a power ratio of $3: 2$ at $511 \mathrm{~nm}$ and $578 \mathrm{~nm}$ wavelengths, and an exposure time of $0.2-0.3 \mathrm{~s}$. Light spot diameter $-1 \mathrm{~mm}$. The treatment was carried out during 2-10 sessions with an interval of $1-2$ months between sessions.

Results. In children and adolescents, the treatment of CMN with CVL dual-wavelengths radiation made it possible to achieve significant clarification of the involved area without hypertrophic scars. The duration of the healing of the irradiated area lasted $2-3$ weeks. Side effects were manifested with subtle skin atrophy. Conclusion. The high efficacy of CVL removal of medium-sized CMN in infants and children using the dual-wavelengths CVL radiation without pronounced side effects allows introducing such an approach in the clinical practice of pediatric dermatologists and cosmetologists.

Keywords: copper vapor laser, pigmented skin defects, congenital melanocytic nevi.

Conflict of interest: the authors state that there is no potential conflict of interest requiring disclosure in this article.

For citation: Igor V. Ponomarev, Sergei B. Topchy, Alexandra E. Pushkareva, Yury N. Andrusenko,

Ludmila D. Shakina. Treatment of congenital melanocytic nevus in infants and children by a dual-wavelengths copper vapor laser. Vestnik Dermatologii i Venerologii. 2020; 96 (3): 43-52. https://doi.org/10.25208/vdv1133 
Введение

Врожденные меланоцитарные невусы (ВМН) гамартомы кожи, отличающиеся избыточным количеством гиперпигментированных меланоцитов в эпидермисе и/или в дерме. Наличие ВМН в эстетически значимых зонах может быть связано с косметическим дефектом, что может привести к снижению самооценки и качества жизни ребенка. До последнего времени при выборе лечения ВМН предпочтение отдавалось хирургическим методам коррекции, таким как местная пластика, экспандерная дермотензия и пересадка свободных кожных трансплантатов, иссечение с применением кожной пластики, дермабразия, лазерная абляция, отбеливающие средства [1-3].

Впервые изображение ВМН как заболевания кожи было опубликовано в 1817 г. британским дерматологом Томасом Батеманом (Bateman T. 1778-1821) [4]. Первое клиническое описание ВМН было приведено в 1835 г. фрранцузским врачом Жан-Луи-Марком Алибером (1768-1837) [5].

Частота выявления ВМН у новорожденных достигает 1\% [6]. Окраска и фрорма ВМН определяются их патоморфологическими особенностями - локализацией невусных (опухолевых) меланоцитов в эпидермисе и/или дерме. Более темная окраска кожи в области ВМН свидетельствует о локализации невусных меланоцитов в эпидермисе (эпидермальные ВМН) или на границе между эпидермисом и дермой (пограничные ВМН). Чем светлее окраска ВМН, тем ближе к проксимальной границе дермы расположены невусные клетки и тем меньше пигмента они содержат [7, 8].

Пограничные ВМН представлены плоскими образованиями с четко очерченными контурами и темно-коричневой окраской, диаметром до 5 мм; невусные меланоциты обнаруживаются на границе между эпидермисом и дермой. Для сочетанных ВМН характерно наличие папул с коричневой окраской диаметром до 10 мм. В них невусные меланоциты присутствуют и в эпидермисе, и в дерме. Светло-коричневые ВМН куполообразной формы, иногда с волосистой поверхностью, на ножке или расширенном основании, которые связаны с избыточным содержанием невусных клеток только в дерме, классифицируются как дермальные невусы [9, 10]. Наличие многочисленных мелких невусов вблизи одного большого может быть связано с локализацией меланоцитов не только в дерме, но и в подкожной клетчатке и нижележащих тканях.

Классификация ВМН представлена в табл. 1 [11].

Таблица 1. Классификация ВМН для их стандартизированного описания

Table 1. Classification of Congenital Melanocytic Nevi for their standardized description

\begin{tabular}{|c|c|c|}
\hline Признак & Обозначение & Описание \\
\hline \multirow{11}{*}{$\begin{array}{l}\text { Предполагаемый размер (см) } \\
\text { в зрелом возрасте }\end{array}$} & Малый ВМН & размер $<1,5$ \\
\hline & Средний ВМН & \\
\hline & M1 & $1,5<$ размер $<10$ \\
\hline & M2 & $10<$ размер $<20$ \\
\hline & Большой ВМН & \\
\hline & L1 & $20<$ размер $<30$ \\
\hline & L2 & $30<$ размер $<40$ \\
\hline & Гигантский ВМН & \\
\hline & G1 & $40<$ размер $<60$ \\
\hline & G2 & $60<$ размер \\
\hline & Средние множественные ВМН & $\begin{array}{c}\geq 3 \text { ВМН среднего размера при отсутствии } \\
\text { доминирующего ВМН }\end{array}$ \\
\hline \multicolumn{3}{|l|}{ Локализация } \\
\hline Голова & Лицо, череп & \\
\hline Туловище & $\begin{array}{l}\text { Шея, плечо, верхняя часть спины, нижняя часть спины, } \\
\text { грудные железы/грудь, живот, бок, ягодицы, гениталии }\end{array}$ & \\
\hline Конечности & Плечо, предплечье, кисть, бедро, голень, стопа & \\
\hline \multirow{4}{*}{ Количество сателлитов } & So & Нет \\
\hline & S1 & $<20$ \\
\hline & S2 & $20-50$ \\
\hline & S3 & $>50$ \\
\hline \multirow{4}{*}{$\begin{array}{l}\text { Дополнительные } \\
\text { морфологические } \\
\text { характеристики }\end{array}$} & $\mathrm{C} 0, \mathrm{C} 1, \mathrm{C} 2$ & $\begin{array}{c}\text { Окраска: равномерная окраска, } \\
\text { умеренно неравномерная, выраженная } \\
\text { гетерогенность окраски }\end{array}$ \\
\hline & $\mathrm{R} 0, \mathrm{R} 1, \mathrm{R} 2$ & Гладкая, неровная, шероховатая \\
\hline & N0, N1, N2 & $\begin{array}{l}\text { Узлов нет, единичные, выраженные узлы } \\
\text { в дерме и подкожной клетчатке }\end{array}$ \\
\hline & $\mathrm{H} 0, \mathrm{H} 1, \mathrm{H} 2$ & $\begin{array}{l}\text { Волос нет, различимые волоски, } \\
\text { выраженный гипертрихоз, волосатость }\end{array}$ \\
\hline
\end{tabular}


Для вычисления предполагаемого окончательного размера ВМН у взрослых по размеру в младенческом возрасте (до 3 лет) следует использовать коэффициенты роста: при локализации на голове - 1,7; на ногах 3,3; при иной локализации - 2,8.

Частота перерождения в меланому ВМН мелкого и среднего размера не превышает 1\%, для крупных и гигантских ВМН она достигает 5\% [12]. У младенцев невусы подразделяют на малые (менее 0,5 см в диаметре), средние (0,5-0,7 см), крупные (>7 см в диаметре в области позвоночника, ягодиц или конечностей или >12 см в области головы) и гигантские (>14 см) [13]. К гигантским ВМН относятся также локализованные на лице невусы, площадь которых превышает 1\% от площади поверхности тела, или локализованные на других участках тела невусы, площадь которых превышает 2\% площади поверхности тела. Частота малигнизации гигантских ВМН достигает 31\% [14].

При наличии изолированного ВМН небольшого размера риск его трансформации в меланому невелик. Трансформация ВМН в меланому в половине случаев происходит в первые пять лет жизни, в 10\% этот процесс инициируется в пубертатном периоде [15-17]. Полное и своевременное удаление ВМН признано эффективным методом профилактики развития меланомы [17].

\section{Патоморфология и патогенез ВMH}

В отличие от врожденных дермальных меланоцитозов, а также невусов Оты и Ито, ВМН состоят из гнездных скоплений невомеланоцитов. По степени зрелости выделяют три типа невомеланоцитов. Невусные клетки типа А сходны со зрелыми меланоцитами в эпидермисе, локализуются в эпидермисе и верхних слоях дермы, содержат большое количество пигмента и образуют крупные гнезда. Менее зрелые меланоциты типа В образуют гнезда небольших размеров в средней части дермы. Незрелые меланоциты типа C не образуют четко выраженных гнезд, отличаются веретенообразной фрормой и малым содержанием пигмента [18]. Появление невусных клеток, как и клеток меланомы, инициируется онкогенной мутацией митоген-активированной протеинкиназы, чаще всего мутацией, активирующей ген BRAF V600E [19]. Как и меланомные клетки, невомеланоциты экспрессируют плюрипотентные гены Oct4, Nestin and Sox10 [20]. В гигантских и больших ВМН, связанных с повышенным риском трансформации в меланому, количество невусных клеток, экспрессирующих плюрипотентные гены, значительно больше, чем в ВМН среднего размера [21].

\section{Лечение ВМH}

Лечение ВМН хирургическими методами может оказаться затруднительным из-за локализации невуса на открытых частях тела, особенно в периорбитальной области, а также из-за больших размеров области пигментации.

Основным преимуществом лазерной терапии по сравнению с традиционными методами лечения ВМН является возможность использования селективного фрототермолиза для селективной фотодеструкции меланосом без выраженного термического повреждения окружающих клеток и коллагеновых структур. С помощью лазеров может быть достигнут отличный косметический результат при минимальном риске образования рубцов.
Пациенты, как правило, хорошо переносят лечение лазером. Для селективной лазерной обработки ВМН применяются различные лазерные аппараты видимого диапазона спектра (импульсный лазер на красителе, вторая гармоника Nd:YAG-лазера с длиной волны 532 нм) и лазерные системы ближнего инфракрасного спектра (рубиновый, александритовый и Nd:YAG-лазеры как с модуляцией добротности, так и в длинноимпульсном режиме). Однако существует риск образования рубцов, осложнений и репигментации, поэтому требуется тщательный подбор режима лазерного воздействия в зависимости от типа и окраски ВМН.

Нами впервые приводится описание опыта лечения ВМН излучением двухволнового ЛПМ у детей.

\section{Материал и методы}

Лечение проводилось у девяти светлокожих пациентов с ВМН, тип I, в том числе у двух мальчиков и семи девочек в возрасте от 2 месяцев до 16 лет (см. табл. 2). Критерии включения пациентов в исследование были следующими: диагноз одиночного ВМН был поставлен с раннего детства и подтвержден дерматоскопическими и гистологическими данными; отсутствие меланомы в анамнезе пациента и у его родственников. До процедуры выполнялась дерматоскопия, которая показала наличие симметричной типичной пигментной сетки коричневого цвета с интенсивной окраской в центре и затуханием к периферии, относительно однородную структуру, одиночные черные точки на перегородках, отсутствие бело-голубых элементов.

Гистологическое исследование показало: лимфоидный инфильтрат верхних отделов дермы. Клиновидные пучки меланоцитов.

Характерно присутствие меланоцитов в придатках кожи, вокруг сосудов, незначительно в сальных железах.

\section{Заключение - врожденный меланоцитарный невус.}

\section{Описание лазерной процедуры}

Исследование проводилось в соответствии с Хельсинкским протоколом. Во всех случаях было получено информированное согласие родителей пациентов на участие в исследовании. Для лечения ВМН использовался аппарат лазерный медицинский на парах меди Яхрома-Мед (Физический институт им. П.Н. Лебедева РАН), работающий на длинах волн 511 и 578 нм с длительностью импульсов генерации 20 нс и с частотой следования импульсов 16,6 кГц. При проведении процедуры были выбраны следующие параметры ЛПМ: средняя мощность 0,6-1,0 Вт при соотношении мощностей излучения на зеленой (511 нм) и желтой (578 нм) длинах волн 3:2. Длительность экспозиции 0,2-0,3 с. Диаметр светового пятна на поверхности кожи - 1 мм, расстояние между центрами световых пятен - 1 мм.

Критерием выбора энергии импульса было установлено максимальное посерение пигмента без его повреждения. Чем светлее окраска $\mathrm{BMH}$, тем больше выбиралась мощность и экспозиция.

Сразу после процедуры окраска обработанной области приобретала сероватый оттенок, сохранявшийся несколько дней. На вторые-третьи сутки фрормировалась безболезненная сплошная коричневая сухая корочка по всей площади лазерного воздействия. После 
Таблица 2. Описание пациентов

Table 2. Patient description

\begin{tabular}{|c|c|c|c|c|c|c|c|c|c|}
\hline № & $\begin{array}{c}\text { Фототип } \\
\text { кожи по } \\
\text { Фитцпатрику }\end{array}$ & Возраст & Пол & Локализация & $\begin{array}{c}\text { Гистологический } \\
\text { тип невуса, } \\
\text { классификация } \\
\text { ВМН }\end{array}$ & $\begin{array}{l}\text { Размеры, } \\
\text { мм }\end{array}$ & $\begin{array}{l}\text { Число } \\
\text { процедур } \\
\text { ЛПМ }\end{array}$ & $\begin{array}{c}\text { Время } \\
\text { заживления, } \\
\text { недели }\end{array}$ & $\begin{array}{c}\text { Результат } \\
\text { лечения по } \\
10-\text { балльной } \\
\text { шкале }\end{array}$ \\
\hline 1 & 1 & 2 мес. & Д & Щека & $\begin{array}{l}\text { Пограничный } \\
\text { M1SOC1RONOHO }\end{array}$ & $17 \times 26$ & 9 & 2 & 9 \\
\hline 2 & 2 & 5 & M & $\begin{array}{c}\text { Левая лобно-височная } \\
\text { область }\end{array}$ & $\begin{array}{l}\text { Пограничный } \\
\text { M1SOC1R2NOH2 }\end{array}$ & $90 \times 50$ & 10 & 2 & 8 \\
\hline 3 & 2 & 14 & Д & $\begin{array}{c}\text { Периорбитальная } \\
\text { область слева }\end{array}$ & $\begin{array}{l}\text { Пограничный } \\
\text { M1SOC1R2NOH1 }\end{array}$ & $26 \times 19$ & 2 & 3 & 8 \\
\hline 4 & 2 & 5 & M & Крыло, область носа & $\begin{array}{c}\text { Пограничный } \\
\text { M1S1C1R1N0H1 }\end{array}$ & $30 \times 14$ & 7 & 3 & 8 \\
\hline 5 & 2 & 12 & Д & Левая щека & $\begin{array}{l}\text { Пограничный } \\
\text { M1SOC1RONOH1 }\end{array}$ & $12 \times 15$ & 6 & 3 & 8 \\
\hline 6 & 2 & 12 & Д & $\begin{array}{c}\text { Периорбитальная область } \\
\text { справа }\end{array}$ & $\begin{array}{l}\text { Пограничный } \\
\text { M1S0C2R1N1H1 }\end{array}$ & $19 \times 16$ & 7 & 2 & 8 \\
\hline 7 & 2 & 17 & Д & $\begin{array}{c}\text { Переносица и частично } \\
\text { лобная область }\end{array}$ & $\begin{array}{l}\text { Пограничный } \\
\text { M1SOC2R2N1H2 }\end{array}$ & $18 \times 30$ & 5 & 2 & 8 \\
\hline 8 & 2 & 4 & Д & $\begin{array}{c}\text { Передняя поверхность } \\
\text { верхней трети левого бедра }\end{array}$ & $\begin{array}{l}\text { Пограничный } \\
\text { M1SOCORONOHO }\end{array}$ & $7 \times 9$ & 6 & 3 & 8 \\
\hline 9 & 2 & 16 & Д & $\begin{array}{c}\text { Передняя латеральная } \\
\text { поверхность нижней трети } \\
\text { правой голени }\end{array}$ & $\begin{array}{l}\text { Пограничный } \\
\text { M1SOC1RONOH1 }\end{array}$ & $90 \times 35$ & 5 & 3 & 9 \\
\hline
\end{tabular}

лазерного воздействия кожу дезинфицировали 0,05\% раствором хлоргексидина с последующим нанесением крема Бепантен дважды в сутки с соблюдением особой осторожности, чтобы не повредить корочку. Период заживления длился 10-12 суток.

Через 10-12 суток корочки отторгались с формированием розового эпидермиса без коричневой пигментации. Через 3-4 недели после проведения лазерной процедуры окраска участка кожи в основном восстанавливалась до нормальной без формирования рубцов или с незначительной атрофией кожи.
Клинический случай 1.

Из анамнеза. ВМН размером $18 \times 25$ мм на щеке у девочки (возраст - 2 месяца) существует с рождения: $\mathrm{BMH}$ I типа, M1SOC1RONOH0, локализация - лицевая область справа (рис. 1).

Лечение начали в возрасте 2 месяцев без применения анестезии. Было проведено 9 сеансов с интервалом 1-2 месяца. Повторное изображение получено в возрасте 1,5 и 5 лет.

Лазерное лечение позволило добиться существенного осветления кожи в области патологического очага.

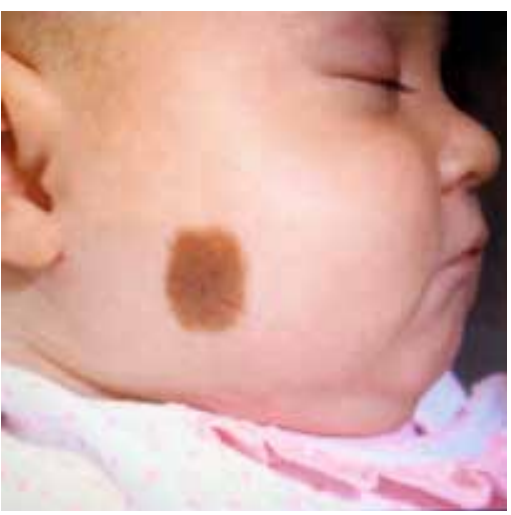

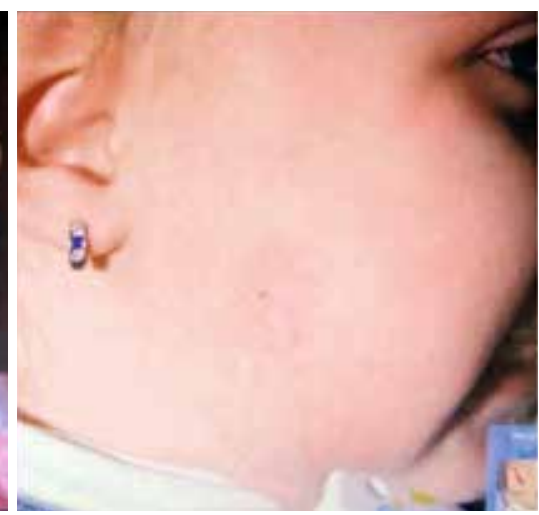

$\sigma$

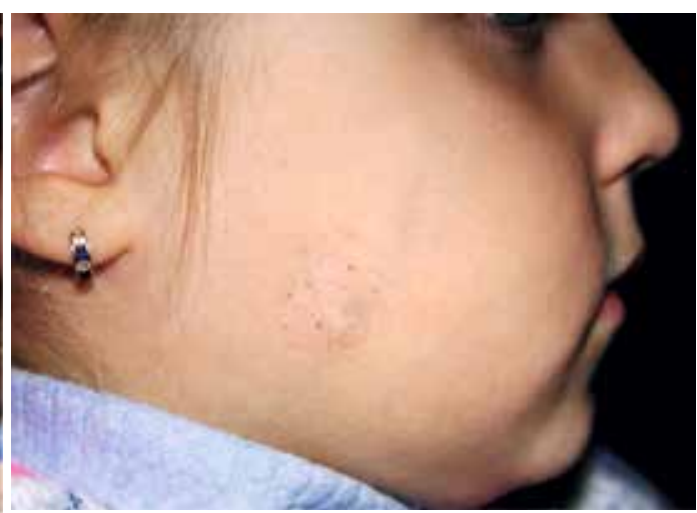
Рис. 1. Врожденный меланоцитарный невус I типа у девочки (возраст - 2 месяца) на коже щеки размером $18 \times 25$ мм, M1SOC1RONOHO: (a) до лечения, (б) после
9 сеансов лазеротерапии в возрасте 1,5 года и (в) в отдаленном периоде после лечения ( 5 лет) (пациент № 1 , табл. 2)
Fig. 1. Congenital melanocytic nevus type I in a girl (age-2 months) on the skin of the cheek sized of $18 \times 25 \mathrm{~mm}, \mathrm{M} 1 \mathrm{SOC} 1 \mathrm{RONOHO}$ : (a) before treatment, (b) after 9 sessions of the
laser treatment y at the age of 1.5 years, and (b) following the long-term period after treatment ( 5 years) (patient \# 1, table 2) 


\section{Клинический случай 2.}

Из анамнеза. На рис. 2 представлено изображение лобно-височной области с ВМН среднего размера до, в процессе и после лечения ВМН I типа, M1SOC1R2NOH2 размером $90 \times 50$ мм в лобно-височной области слева, у мальчика 5 лет.

Фото были сделаны до лечения, после проведения тестовой пробы и через три года после 10 процедур лечения.

\section{Клинический случай 3.}

Из анамнеза. На рис. 3 представлено изображение области носа с ВМН среднего размера до и после лечения $\mathrm{BMH}, \mathrm{M} 1 \mathrm{SOC} 1 \mathrm{R} 2 \mathrm{NOH} 2$ размером $30 \times 14 \mathrm{MM}$ в лобно-височной области слева, у мальчика 5 лет.

\section{Клинический случай 4.}

Из анамнеза. На рис. 4 представлено изображение области передней латеральной поверхности нижней трети правой голени с ВМН среднего размера до и после лечения $\mathrm{BMH}, \mathrm{M} 1 \mathrm{SOC} 1 \mathrm{R} 2 \mathrm{NOH} 2$ размером $90 \times 35$ мм, у девочки 16 лет.
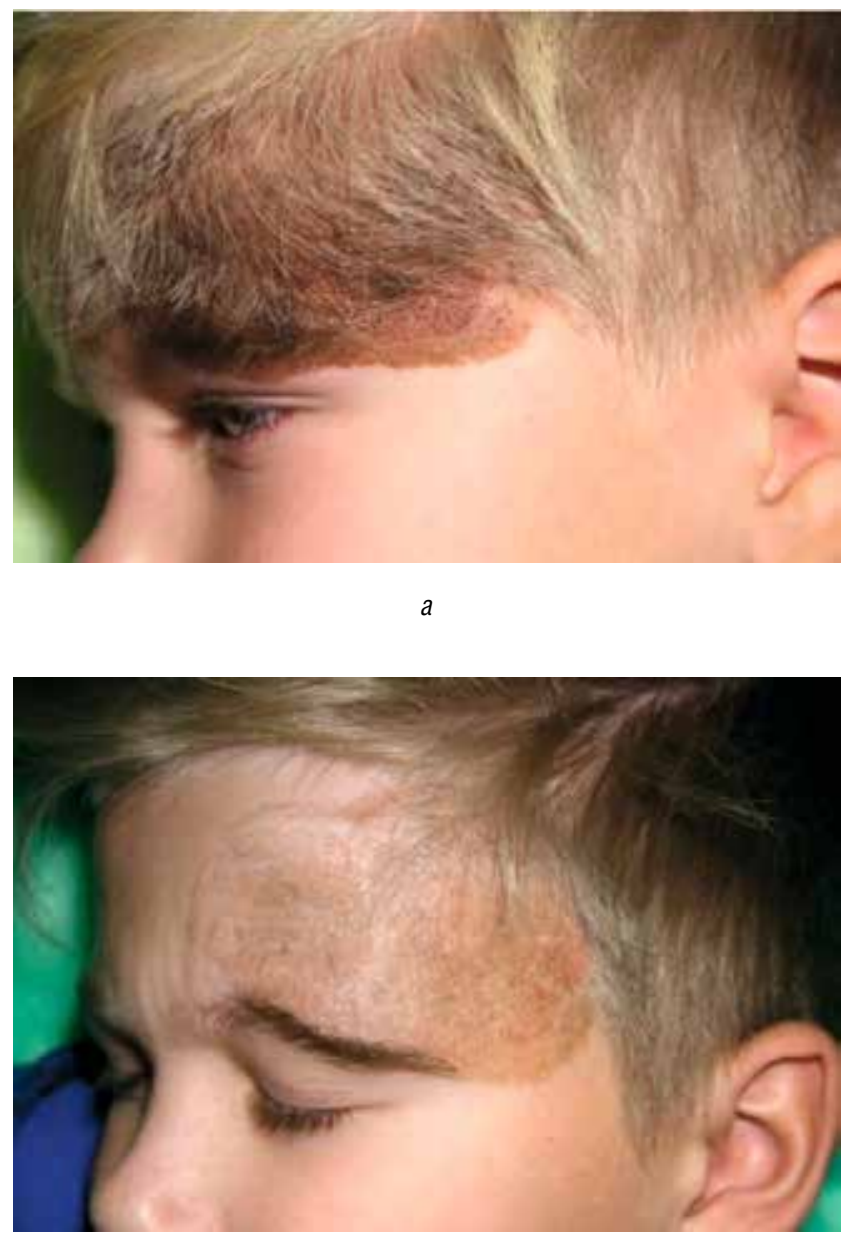

\section{Клинический случай 5.}

Из анамнеза. На рис. 5 представлено изображение области передней латеральной поверхности нижней трети правой голени с ВМН среднего размера до и после лечения $\mathrm{BMH}, \mathrm{M} 1 \mathrm{SOC} 1 \mathrm{R} 2 \mathrm{NOH} 2$ размером 7 × 9 мM, у девочки 4 лет.

\section{Оценка результатов лечения}

Оценка результатов лечения была сделана независимым врачом-дерматологом путем сравнения фотографрий каждого пациента при каждом последующем наблюдении. Численное значение оценки 0-10 (0 - отсутствие улучшения/10 - полное излечение) присваивалось каждой последующей фотографии после сравнения результатов после лечения с фотографиями до лечения. Значения оценки результатов приведены в табл. 2.

У пациентов не было отмечено выраженных побочных эффректов после лечения.

\section{Обсуждение}

В нашей работе впервые описано лечение $\mathrm{BMH}$ двухволновым излучением ЛПМ у детей, которое по-
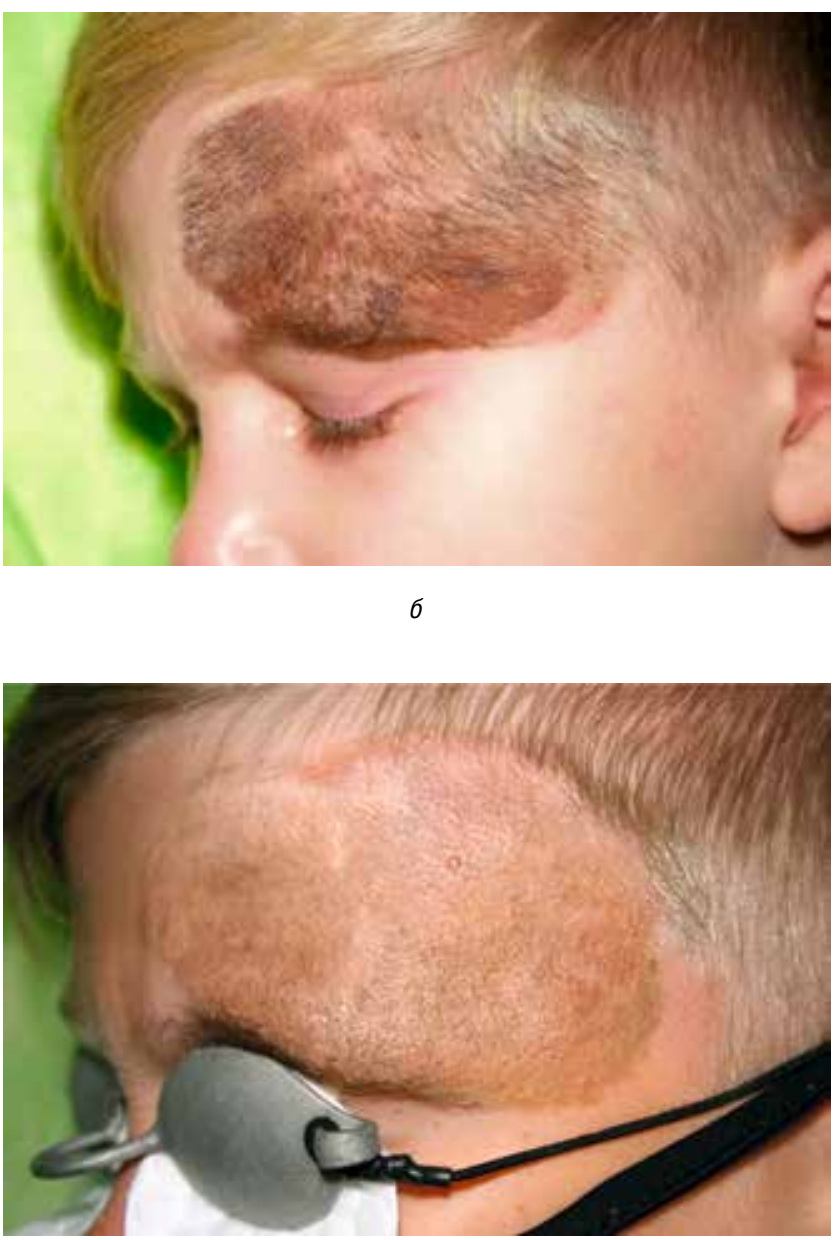

$\Gamma$

\footnotetext{
Рис. 2. BMH I типа размером 90 × 50 мм в лобно-височной области слева, M1SOC1R2NOH2 у мальчика 5 лет: (а) до лечения, (б) после тестовой пробы и (в, Г) через три года после лечения (проведено 10 процедур с интервалом 2-4 месяца) (пациент № 2, табл. 2)

Fig. 2. CMN Type I sized of $90 \times 50 \mathrm{~mm}$ in the left frontotemporal area, M1SOC1R2NOH2 in a 5-year-old boy: (a) before treatment, (b) after a test sample, and $(c, d)$ three years after the treatment (10 procedures were performed at $2-4$ month intervals) (patient \# 2, table 2)
} 


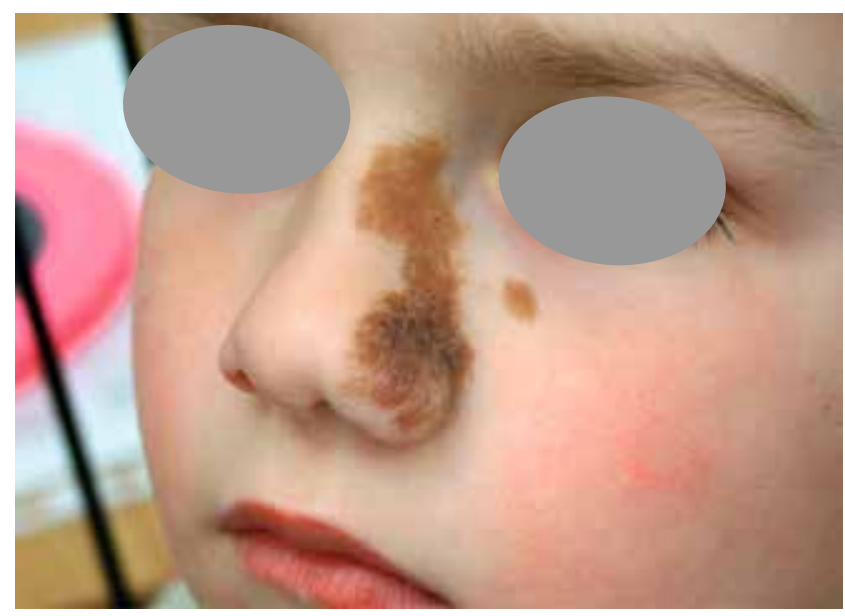

a

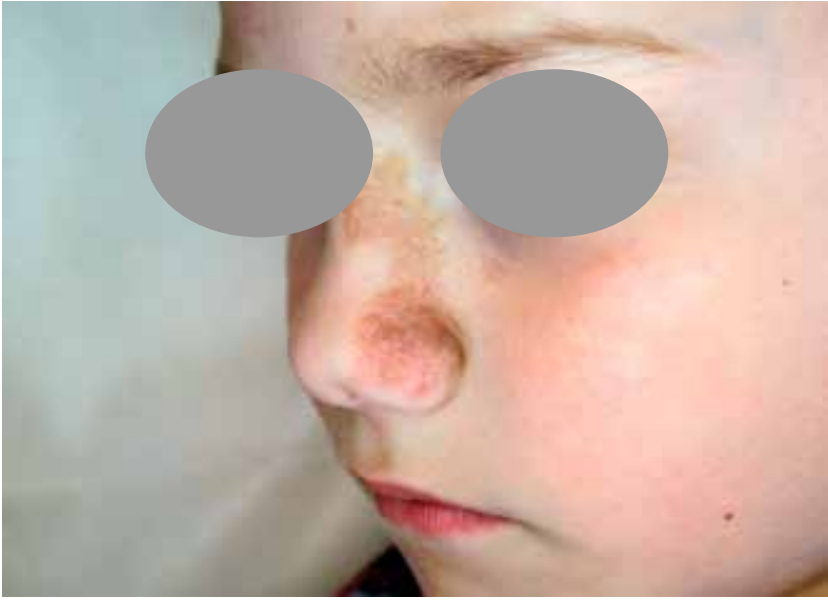

6

Рис. 3. ВMH I типа размером 30 × 14 мм в области носа слева, M1S1C1R1NOH1 у мальчика 5 лет: (а) - до лечения, через 1,5 года после лечения (проведено 7 процедур с интервалом 2 месяца) (б) (пациент № 4, табл. 2)

Fig. 3. CMN Type I sized of $30 \times 14 \mathrm{~mm}$ in the left nasal area, M1S1C1R1NOH1 in a 5-year-old boy: (a) before treatment, $(b)$ after 1,5 years after the treatment (7 procedures were performed at 2 months intervals) (patient \# 4, table 2)

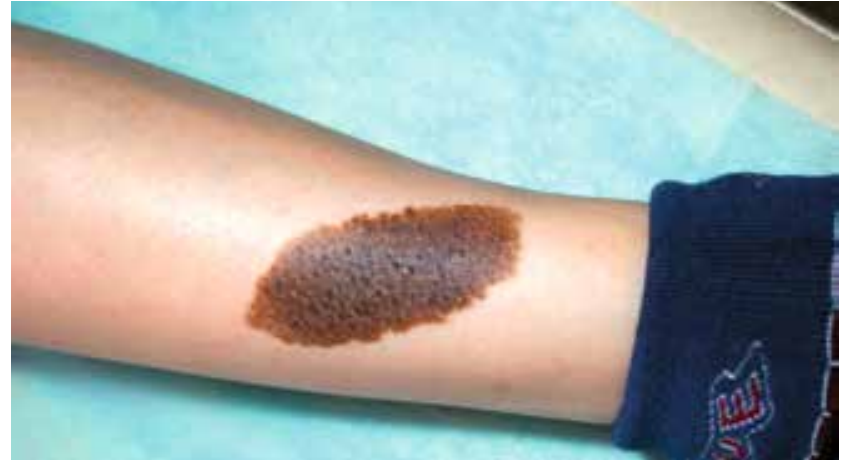

a

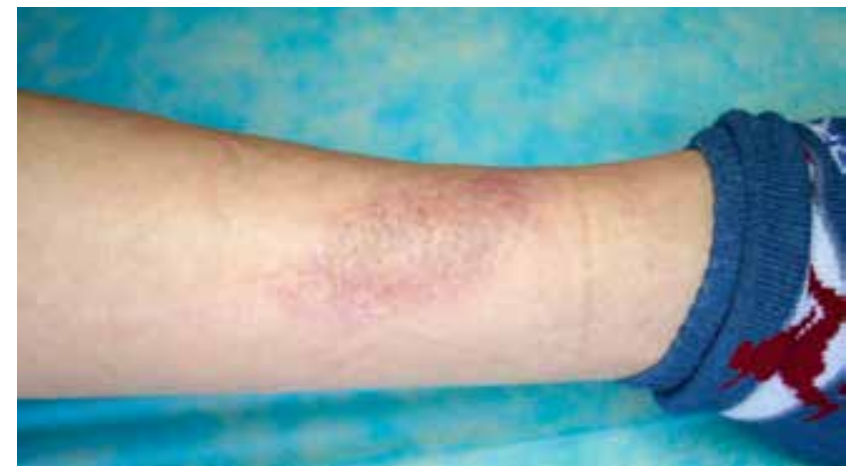

$\sigma$

Рис. 4. BMH размером 90 × 35 мм в области передней латеральной поверхности нижней трети правой голени, M1SOC1RONOH1 у девочки 16 лет: (a) — до лечения и через год после лечения (проведено 5 процедур с интервалом 2 месяца) (б) (пациент № 9, табл. 2)

Fig. 4. CMN Type I sized of $90 \times 35 \mathrm{~mm}$ in the Anterior lateral surface of the lower third of the right shin, M1SOC1RONOH1 in a 16-year-old girl: (a) before treatment, (b) after 1 year after the treatment (5 procedures were performed at 2 months intervals) (patient \# 9, table 2)

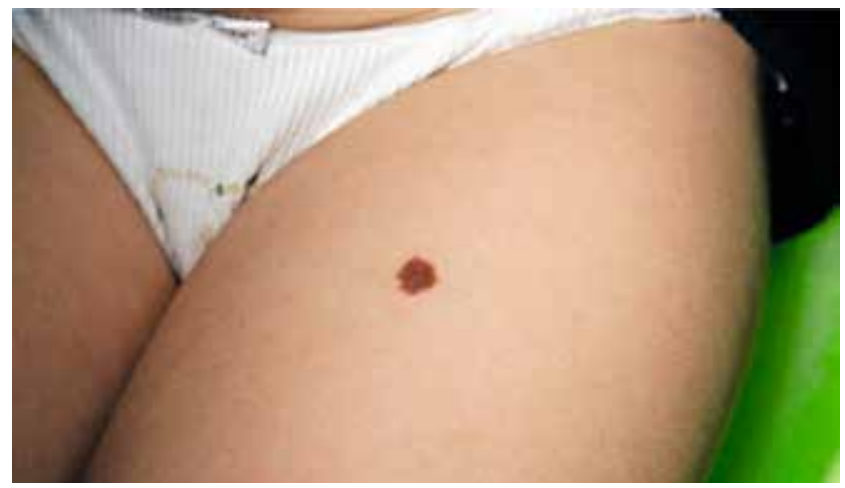

$a$

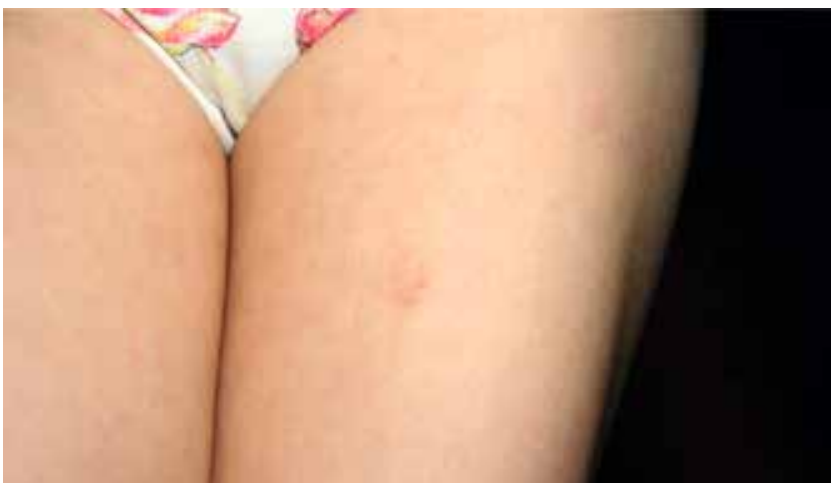

$\sigma$

Pис. 5. ВMH размером 7 × 9 мм в области передней поверхности верхней трети левого бедра, M1SOCORONOHO у девочки 4 лет до лечения (a) и через год после лечения (проведено 6 процедур с интервалом 2 месяца) (б) (пациент № 8, табл. 2)

Fig. 5. CMN Type I sized of $7 \times 9 \mathrm{~mm}$ in the anterior surface of the upper third of the left thigh, M1SOCORONOHO in a 4-year-old: (a) before treatment, $(b)$ after 1 year after the treatment (6 procedures were performed at 2 months intervals) (patient \# 8, table 2) 
зволило добиться заметного осветления ВМН среднего размера без отдаленных побочных эфрфектов (рубцевания или повторной пигментации). Побочные эффректы были выражены малозаметной атрофией кожи.

Для лечения ВМН были опробованы различные лазерные системы и их комбинации с переменным успехом. С абляционными лазерами (CO2 и Er:YAG) получены успешные результаты лечения, однако отмечался высокий риск образования рубцов [22]. В настоящее время для лечения ВMH CO2 и Er:YAG лазеры применяются в сочетании с неабляционными системами.

Внедрение в клиническую практику лазеров с модуляцией добротности (рубиновый, александритовый, неодимовый), которые могут селективно воздействовать на пигмент согласно принципу селективного фрототермолиза, позволило лечить ВМН с более низкой частотой осложнений. Однако при применении этих лазерных систем отмечался высокий риск рецидивов. После лечения ВМН с использованием рубинового лазера у всех пациентов происходило частичное осветление пигментированной области, но через несколько месяцев наблюдалась повторная пигментация, и результат в итоге оказывался неудовлетворительным [23]. Для достижения лучшего осветления ВMH и уменьшения частоты рецидивов использовалась комбинация абляционного лазера для испарения эпидермиса с последующей обработкой селективным лазером с модуляцией добротности или IPL $[24,25]$. Тем не менее через год после обработки Er:YAG-лазером в комбинации c IPL была получена частота рецидивов ВМН до $82 \%$ [24]. Важно отметить, что приведенные выше методики не приводили к полному осветлению невуса за одну обработку лазером. Требовалось как минимум 4 процедуры с интервалом 4 месяца между ними.

Гистологические исследования после лечения ВМН рубиновым и неодимовым лазерами с модуляцией добротности показали, что рецидив связан с неполным разрушением всех невомеланоцитов [26].

В недавней работе [27] для осветления ВМН у детей использовались последовательно три лазера: лазер на красителе (595 нм), рубиновый лазер (694нм) и фрракционный СО2 лазер (10,6 мкм), причем чем раньше было начато лечение лазером, тем лучше получался результат. Особенно этот эфффект отмечался на новорожденных с тонкой кожей, что объясняется миграцией меланоцитов с возрастом в более глубокие слои кожи [1].

В табл. 3 приведены значения поглощения меланином (https://omlc.org/spectra/melanin/mua.html) для различных длин волн, соответствующих применяемым для лечения $\mathrm{BMH}$ лазерам. Можно отметить более чем десятикратное изменение величины поглощения меланином от зеленой длины волны к ближнему ИК-диапазону.
Таким образом, выбор лазера с зеленой и желтой длинами волн обеспечивает максимальную селективность воздействия на пигмент для лечения ВМН и двухволновое излучение ЛПМ, которое соответствует высокому поглощению меланина (длина волны 511 нм) и совпадает с локальным максимумом поглощения оксигемоглобина (длина волны 578 нм), может быть эффективно использовано для лечения ВМН.

Гистологические данные после обработки импульсным лазером на красителе с различными длинами волн (504, 590, 694, 720, 750 нм) продемонстрировали максимальную селективность и наиболее специфричное повреждение меланосом на зеленой длине волны 504 нм, что близко к длине волны генерации ЛПМ 511 нм [28]. Излучение ЛПМ с длиной волны 511 нм успешно было использовано для лечения эпидермальных пигментированных дефектов кожи $[29,30]$. Применение излучения ЛПМ с длинами волн 578 и 511 нм позволило добиться высокой эффрективности осветления гиперпигментированного эпидермиса при лечении мелазмы и поствоспалительной гиперпигментации в работе [31].

Существенным условием селективности лазерного воздействия является выбор оптимальной длительности лазерного импульса. Согласно принципу селективного фоототермолиза, использование лазерного излучения с длительностью импульса, не превышающей время тепловой релаксации (ВТР) целевого хромофора ткани-мишени, минимизирует термическое повреждение окружающей ткани. ВТР определяется размером ткани-мишени. В ВМН представлены как изолированные пигментированные меланосомные клетки (размер около 7 мкм и ВТР не более 1 мкс), так и кластеры (гнезда, конгломераты), состоящие из пигментных клеток (размер кластера составляет около 100 мкм и ВТР около 10-100 мс) [10]. Следовательно, идеальный лазер для обработки ВМН должен обеспечивать селективное воздействие на ВМН как короткими наносекундными импульсами, так и длинными миллисекундными импульсами.

Такой комбинированный режим воздействия обеспечивает излучение ЛПМ. Каждый импульс ЛПМ имеет длительность 20 нс и пиковую мощность до нескольких кВт. При воздействии на кожу электромеханическим затвором формируется серия импульсов ЛПМ с длительностью 100-200 мс.

Данные оптической когерентной томографии свидетельствуют о двукратном увеличении васкуляризации в области ВМН [32]. Для предотвращения рецидива ВМН целесообразно обеспечить ремоделирование сосудистого русла, связанного с гиперпигментацией [33]. Для этой цели эфффективно используется излучение ЛПМ на желтой длине волны 578 нм,

\section{Таблица 3. Значения поглощения меланина для длин волн различных лазеров} Table 3. Melanin absorption values for different laser wavelengths

\begin{tabular}{cccccc}
\hline Тип лазера & лпМ & лпМ & Рубиновый & Александритовый & Неодимовый \\
\hline Длина волны, нм & 511 & 578 & 694 & 755 & 1060 \\
\hline Поглощение меланином, см ${ }^{-1}$ & 638,47 & 415,85 & 220,04 & 164,13 & 50,39 \\
\hline
\end{tabular}


которое обеспечивает селективный нагрев диспластических сосудов в области ВМН [30, 34].

Благодаря высокому поглощению меланина и оксигемоглобина излучение ЛПМ, в отличие от лазеров ближнего ИК-диапазона, не проходит в ретикулярный слой дермы, не перегревает дермальные стволовые клетки, что обеспечивает быстрое заживление без побочных эфрфектов после лазерной процедуры [30, 34].

Авторы связывают полученные клинические результаты лечения ВМН излучением ЛПМ с высокой селективностью нагрева пигмента и ремоделированием связанного с пигментацией сосудистого русла.

\section{Заключение}

Высокая эфффективность лечения и отсутствие отдаленных побочных эфрфектов в описанных случаях лечения ВМН с применением двухволнового лазерного воздействия свидетельствуют об эфффективной элиминации дермального меланоцитоза и полноценном ремоделировании сосудистого русла в сосочковом слое дермы в области лазерного воздействия на патологический очаг ВМН. Применение двухволнового излучения ЛПМ для лечения ВМН у детей демонстрирует отличные косметические результаты и представляет собой альтернативу хирургическим методам. Предпочтительно проводить лечение ВМН в детском возрасте, так как с возрастом глубина расположения невусных клеток увеличивается, что усложняет лечение. Выбор оптимальных параметров ЛПМ для лечения различных типов ВМН будет предметом отдельного исследования с большим количеством пациентов и продолжительным периодом наблюдения.

\section{Литература/References}

1. Sandsmark M., Eskeland G., Ogaard A.R., Abyholm F., Clausen 0.P. Treatment of large congenital naevi. A review and report of six cases. Scand J Plast Reconstr Surg Hand Surg. 1993; 27 (3): 223-232. doi:10.3109/02844319309078115.

2. Reyes-Mugica M., Alvarez-Franco M., Bauer B.S., Vicari F.A. Nevus cells and special nevomelanocytic lesions in children. Pediatr Pathol. 1994; 14 (6): 1029-1041. doi:10.3109/15513819409037699.

3. Bray F.N., Shah V., Nouri K. Laser treatment of congenital melanocytic nevi: a review of the literature. Lasers Med Sci. 2016; 31 (1): 197-204. doi:10.1007/s10103-015-1833-3.

4. Bateman T., Willan R. Delineations of cutaneous diseases: exhibiting the characteristic appearances of the principal genera and species comprised in the classification of the late Dr. Willan and completing the series of engravings begun by that author. Longman, Hurst, Rees, Orme, and Brown, 1817.

5. Alibert J.L.M. Monographie des dermatoses ou précis théoretique et pratique des maladies de la peau, vol II: Naeve-Naevus // Daynac, Paris. 1832. C. $729-736$.

6. Price H.N., Schaffer J.V. Congenital melanocytic nevi-when to worry and how to treat: Facts and controversies. Clin Dermatol. 2010; 28 (3): 293_302. doi:10.1016/j.clindermatol.2010.04.004.

7. Damsky W.E., Bosenberg M. Melanocytic nevi and melanoma: unraveling a complex relationship. Oncogene. 2017; 36 (42): 5771—5792. doi:10.1038/onc.2017.189.

8. Sakai H., Ando Y., Ikinaga K., Tanaka M. Estimating melanin Iocation in the pigmented skin lesions by hue-saturation-lightness color space values of dermoscopic images. J Dermatol. 2017; 44 (5): 490_498. doi:10.1111/1346-8138.13725

9. Молочков В.А., Махнева Н.В., Белова И.И., Сухова Т.Е. Гигантский врожденный меланоцитарный невус. Российский журнал кожных и венерических болезней. 2005; 2: 4-7. [Molochkov V.A., Makhneva N.V., Belova I.I., Sukhova T.E. Giant congenital melanocytic nevus. Russian journal of skin and venereal diseases (Rossiyskiy zhurnal kozhnykh i venericheskikh bolezney). 2005; 2: 4-7 (Russia).]

10. Sardana K., Chakravarty P., Goel K. Optimal management of common acquired melanocytic nevi (moles): current perspectives. Clin Cosmet Investig Dermatol. 2014; 7: 89_103. Published 2014 Mar 19. doi:10.2147/ CCID.S57782

11. Krengel S., Scope A., Dusza S.W., Vonthein R., Marghoob A.A. New recommendations for the categorization of cutaneous features of con- genital melanocytic nevi. J Am Acad Dermatol. 2013; 68 (3): 441—451. doi:10.1016/j.jaad.2012.05.043.

12. Magaña M., Sánchez-Romero E., Magaña P., Beck-Magaña A., Magaña-Lozano M. Congenital melanocytic nevus: two clinicopathological forms. Am J Dermatopathol. 2015; 37 (1): 31-37. doi:10.1097/ DAD.0000000000000183.

13. McLaughlin M.R., O'Connor N.R., Ham P. Newborn skin: Part II. Birthmarks. Am Fam Physician. 2008; 77 (1): 56-60.

14. Turkmen A., Isik D., Bekerecioglu M. Comparison of classification systems for congenital melanocytic nevi. Dermatol Surg. 2010; 36 (10): 1554-1562. doi:10.1111/j.1524-4725.2010.01641.x.

15. Fahradyan A., Wolfswinkel E.M., Tsuha M. et al. Cosmetically Challenging Congenital Melanocytic Nevi. Ann Plast Surg. 2019; 82 (5S Suppl 4): S306-S309. doi:10.1097/SAP.0000000000001766.

16. Усольцева А.С., Степанова Ю.В., Красногорский И.Н. \& Цыплакова М.С. Большие и гигантские меланоцитарные невусы челюстно-лицевой области у детей. Особенности морфологического строения и хирургического лечения. Ортопедия, травматология и восстановительная хирургия детского возраста, 2015; 3 (4): 22-28. [Usoltseva A.S., Stepanova Y.V., Krasnogorskiy I.N., Tsyplakova M.S. Large and Giant Melanocytic Nevi of the Maxillofacial Area in Children: Features of the Morphological Structure and Surgical Treatment (Russia).]

17. Zaal L.H., Mooi W.J., Sillevis Smitt J.H., van der Horst C.M. Classification of congenital melanocytic naevi and malignant transformation: a review of the literature. Br J Plast Surg. 2004; 57 (8): 707—719. doi:10.1016/.j.bjps.2004.04.022.

18. Damsky W.E., Bosenberg M. Melanocytic nevi and melanoma: unraveling a complex relationship. Oncogene. 2017; 36 (42): 5771—5792. doi:10.1038/onc.2017.189.

19. Basu D., Salgado C.M., Patel J.R. et al. Pluripotency markers are differentially induced by IGF1 and bFGF in cells from patients' lesions of large/giant congenital melanocytic nevi. Biomark Res. 2019; 7: 2. Published 2019 Jan 14. doi:10.1186/s40364-018-0152-9.

20. Charbel C., Fontaine R.H., Kadlub N. et al. Clonogenic cell subpopulations maintain congenital melanocytic nevi. J Invest Dermatol. 2015; 135 (3): 824-833. doi:10.1038/jid.2014.437.

21. Guégan S., Kadlub N., Picard A. et al. Varying proliferative and clonogenic potential in NRAS-mutated congenital melanocytic nevi according to size. Exp Dermatol. 2016; 25 (10): 789—796. doi:10.1111/exd.13073. 
22. Bray F.N., Shah V., Nouri K. Laser treatment of congenital melanocytic nevi: a review of the literature. Lasers Med Sci. 2016; 31 (1): 197-204. doi:10.1007/s10103-015-1833-3.

23. Helsing P., Mørk G., Sveen B. Ruby laser treatment of congenital melanocytic naevi--a pessimistic view. Acta Derm Venereol. 2006; 86 (3): 235-237. doi:10.2340/00015555-0041.

24. Lee M.S., Jun H.J., Cho S.H., Lee J.D., Kim H.S. Intense Pulsed Light Alone and in Combination with Erbium Yttrium-Aluminum-Garnet Laser on Small-to-Medium Sized Congenital Melanocytic Nevi: Single Center Experience Based on Retrospective Chart Review. Ann Dermatol. 2017; 29 (1): 39—47. doi:10.5021/ad.2017.29.1.39.

25. Al-Hadithy N., Al-Nakib K., Quaba A. Outcomes of 52 patients with congenital melanocytic naevi treated with UltraPulse Carbon Dioxide and Frequency Doubled Q-Switched Nd-Yag laser. J Plast Reconstr Aesthet Surg. 2012; 65 (8): 1019-1028. doi:10.1016/j. bjps.2012.03.003.

26. Grevelink J.M., van Leeuwen R.L., Anderson R.R., Byers H.R. Clinical and histological responses of congenital melanocytic nevi after single treatment with Q-switched lasers. Arch Dermatol. 1997; 133 (3): $349-353$

27. Funayama E., Yamamoto Y., Oyama A. et al. Combination laser therapy as a non-surgical method for treating congenital melanocytic nevi from cosmetically sensitive locations on the body. Lasers Med Sci. 2019; 34 (9): 1925-1928. doi:10.1007/s10103-019-02753-0.

28. Sherwood K.A., Murray S., Kurban A.K., Tan 0.T. Effect of wavelength on cutaneous pigment using pulsed irradiation. J Invest Dermatol. 1989; 92 (5): 717-720. doi:10.1111/1523-1747.ep12721505.
29. Somyos K., Boonchu K., Somsak K., Panadda L., Leopairut J. Copper vapour laser treatment of café-au-lait macules. Br J Dermatol. 1996; 135 (6): 964—968. doi:10.1046/j.1365-2133.1996.d01-1103.x.

30. Ключарева С.В., Пономарев И.В., Топчий С.Б., Пушкарева А.Е., Андрусенко Ю.Н. Лечение себорейного кератоза лазером на парах меди. Вестник дерматологии и венерологии. 2019; 95 (3): 25-33. https://doi.org/10.25208/0042-4609-2019-95-3-25-33 [Klyuchareva S.V., Ponomarev I.V., Topchiy S.B., Pushkareva A.E., Andrusenko Yu.N. Treatment of seborrheic keratosis with a copper vapour laser. Vestnik Dermatologii Venerologii. 2019; 95 (3): 25—33 (Russia).]

31. Lee H.I., Lim Y.Y., Kim B.J. et al. Clinicopathologic efficacy of copper bromide plus/yellow laser $(578 \mathrm{~nm}$ with $511 \mathrm{~nm})$ for treatment of melasma in Asian patients. Dermatol Surg. 2010; 36 (6): 885-893. doi:10.1111/j.1524-4725.2010.01564.x.

32. Ulrich M., Themstrup L., de Carvalho N. et al. Dynamic Optical Coherence Tomography in Dermatology. Dermatology. 2016; 232 (3): 298311. doi:10.1159/0004447706.

33. Regazzetti C., De Donatis G.M., Ghorbel H.H. et al. Endothelial Cells Promote Pigmentation through Endothelin Receptor B Activation. J Invest Dermatol. 2015; 135 (12): 3096—3104. doi:10.1038/jid.2015.332.

34. Ключарева С.В., Пономарев И.В., Пушкарева А.Е. Лечение сосудистых мальформаций кожи с применением лазеров на парах меди и импульсного лазера на красителе. Вестник дерматологии и венерологии. 2018; 94 (1): 65-75. DOI: 10.25208/0042-4609-2018-94-1-65-75. [Klyuchareva S.V., Ponomarev I.V., Pushkareva A.E. Therapy of Skin Vascular Malformations Using Copper Vapor Laser and Pulsed Dye Laser. Vestnik Dermatologii i Venerologii. 2018; 94 (1): 65—75 (Russia).]

\section{Информация об авторах}

Игорь Владимирович Пономарев - к.ф.-м.н., руководитель проекта Физического института имени П.Н.Лебедева Российской академии наук; тел.: 007-495-8510609; e-mail: iponom@0kb.Ipi.troitsk.ru

Сергей Борисович Топчий - к.ф.-м.н., научный сотрудник Физического института имени П. Н. Лебедева Российской академии наук

Александра Евгеньевна Пушкарева - к.т.н., тьютор кафедры лазерных технологий и систем Санкт-Петербургского национального исследовательского университета информационных технологий механики и оптики (Университет ИТМ0); e-mail: alexandra.pushkareva@gmail.com

Юрий Николаевич Андрусенко - врач-хирург, онкодерматолог, заведующий отделением Медицинского центра «Институт здоровья»; e-mail: ure.doc@rambler.ru

Людмила Диевна Шакина - д.м.н., главный научный сотрудник, Национальный медицинский исследовательский центр здоровья детей; e-mail: shakina@nczd.ru

\section{Information about the authors}

Igor V. Ponomarev — Cand. Sci. (Phys.-Math.), Project manager, P.N. Lebedev Physical Institute of the Russian Academy of Sciences; e-mail: iponom@okb.Ipi.troitsk.ru

Sergei B. Topchy - Cand. Sci. (Phys.-Math.), Senior Researcher, P.N. Lebedev Physical Institute of the Russian Academy of Sciences

Alexandra E. Pushkareva - Cand. Sci. (Engineering), Tutor, Department of Laser Technologies and Systems, Saint Petersburg National Research University of Information Technologies, Mechanics and Optics (ITMO University); e-mail: alexandra.pushkareva@gmail.com

Yury N. Andrusenko - Cand. Sci. (Tech.), Clinic of Aesthetic Medicine. Head of the Laser department of the Health Institute; e-mail: ure.doc@rambler.ru

Ludmila D. Shakina — MD, Ph.D., DSci, chief expert, National Medical Research Center of Children Health; e-mail: shakina@nczd.ru ORCID: https://orcid.org/0000-0002-3811-4367 